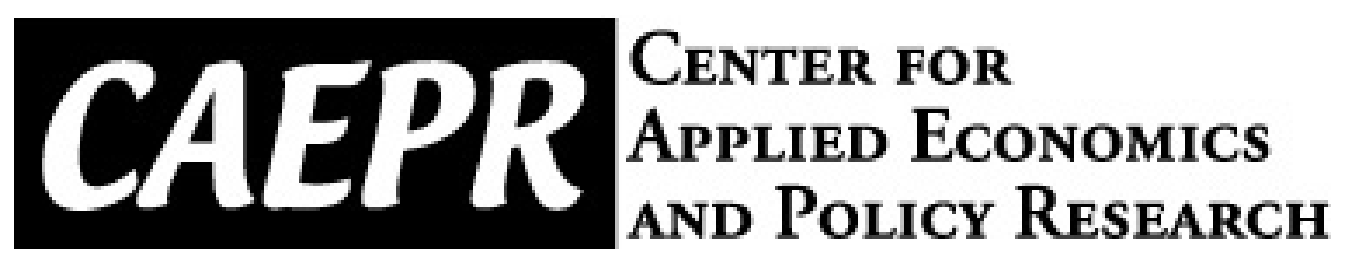

CAEPR Working Paper

\#009-2009

\title{
The Beveridge Curve in the Housing Market: Supply and Disequilibrium
}

\author{
Brian M. Peterson \\ Indiana University
}

June 26, 2009

This paper can be downloaded without charge from the Social Science Research Network electronic library at: http://ssrn.com/abstract=1456351.

The Center for Applied Economics and Policy Research resides in the Department of Economics at Indiana University Bloomington. CAEPR can be found on the Internet at:

http://www.indiana.edu/ caepr. CAEPR can be reached via email at caepr@indiana.edu or via phone at 812-855-4050.

C2008 by NAME. All rights reserved. Short sections of text, not to exceed two paragraphs, may be quoted without explicit permission provided that full credit, including $₫$ notice, is given to the source. 


\title{
The Beveridge Curve in the Housing Market: Supply and Disequilibrium*
}

\author{
Brian M. Peterson ${ }^{\dagger}$ \\ Indiana University
}

June 26, 2009

\begin{abstract}
There is a long-run 'Beveridge Curve' in the Housing market given by the negative relationship between the vacancy rate of housing and the rate of household formation. This is true in the owner-occupied market, the rental market, and the total market for housing irrespective of ownership status. The Beveridge Curve represents a long-run supply condition that can be explained by assuming that (1) the cost to produce a new house is decreasing in the growth rate of the housing stock and (2) the probability to sell a new house is decreasing in the vacancy rate. Short-run deviations from the Beveridge curve represent a measurement of oversupply. Using a years of supply metric, for the total housing market irrespective of ownership, in 2007-2008 there were 0.995 years of supply, more than three times the previous peak of 0.285 years of supply in 1973-1974. Comparing the rental market to the owner-occupied market, oversupply generally shows up in the rental market, not the owner-occupied market and the oversupply in the rental market is twice as volatile as oversupply in the owner-occupied market, implying that a large part of the market adjustment to housing supply occurs in the rental market. Interestingly two-thirds of the oversupply in 2007-2008 resided in the rental market as opposed to the owner-occupied market. Using FHFA data for house prices, $46 \%$ of the movements in oversupply in the owner-occupied market since 1975 can be explained by house price movements. The last result suggests that at short horizons (4-6 years) house prices are not determined by supply. Rather, house prices drive supply at short time horizons, permitting bubbles and oversupplies of housing to form.
\end{abstract}

Keywords: Housing Supply, Vacancy Rates, Oversupply, Rental, Owner-Occupied.

JEL Classification: R3, R31, E32

${ }^{*}$ I thank Kim Huynh for comments and suggestions and Kathleen Macnamara for support and feedback. All errors are the author's alone.

${ }^{\dagger}$ Department of Economics, Indiana University. Wylie Hall 303, 100 S. Woodlawn Ave., Bloomington, IN 47405, USA. E-mail: bripeter@indiana.edu. 


\section{Introduction}

Associated with the current crisis in the housing market is a substantial oversupply of housing units, as evidenced by an unprecedented rise in the owner-occupied vacancy rate to an all time high of $2.9 \%$ in the fourth quarter of 2008 compared to a previous high of $1.9 \%$ between 1956 and 2005. Such an over-accumulation of homes is putting extraordinary downward pressure on house prices, leading to foreclosures and substantial problems in the financial sector. Central to the question of an economic recovery is when will the housing market reach some manner of stability, i.e. when will the housing market be back in equilibrium? For an answer we need to understand what determines equilibrium in the housing market.

To answer this question, this paper borrows the concept of a Beveridge curve from the labor literature. A Beveridge curve is the negative relationship between the unemployment rate and the vacancy rate for jobs, first attributed to Lord Beveridge in his 1944 report (Beveridge 1944). The curve can be thought of as a supply-demand relationship for a scarce resource, workers. The unemployment rate measures the rate of utilization, while the vacancy rate for jobs measures the amount of demand for the scarce resource. The understanding of the Beveridge curve is at the heart of the search and matching literature studying the labor market. ${ }^{1}$

In this paper, I consider an analog in the housing market. In the housing market, the scarce resourse is houses, ${ }^{2}$ so that the the vacancy rate is the equivalent of the unemployment rate. The demand for houses ${ }^{3}$ is given by the rate of household formation. ${ }^{4}$ Using Census data at a biannual frequency from 1965 to 2008, I find that there is a significant negative relationship between the rate of household formation and the residential vacancy rate. I deem this negative relationship 'The Beveridge Curve in the Housing Market.' The negative relationship holds in the owner-occupied market, the rental market, and the total market irrespective of ownership.

The negative relationship between the rate of household formation and the vacancy rate can be thought of as a long-run supply condition. The negative relationship can be generated within a model by assuming that (1) the cost to produce a new house is decreasing in the growth rate of the housing stock and (2) the probability to sell a new house is decreasing in the vacancy rate. Under these assumptions, a fall in the growth rate of households lowers the cost to builders to construct the houses to meet the demand of new

\footnotetext{
${ }^{1}$ For an excellent overview of the Beveridge curve see Yashiv (2008) or the textbook treatment in Pissarides (2000). For an application of the Beveridge curve see Shimer (2005). For a constantly updated Beveridge curve see Rob Shimer's website: http://robert.shimer.googlepages.com/

${ }^{2}$ Although in Summer 2009 the thought of a house as a 'scarce' resource seems a bit misplaced.

${ }^{3}$ This analysis ignores second homes and vacation homes.

${ }^{4}$ It is a bit unfortunate that 'vacancy rate' switches sides from labor to housing, being the measure of demand in the labor market, but then the measure of utilization of the scarce resource in the housing market. I could have used the term 'job posting rate' for the labor market, but 'vacancy rate' is more generally used, so I do likewise here.
} 
households. In conventional frictionless economic theory a fall in the cost of production would fully translate into lower prices. However, if builders are also concerned with the probability that a house can be sold, ${ }^{5}$ then, in addition to lower prices, part of the lower cost of production could show up in a lower probability of sale. Therefore, under the second assumption, the market adjusts not only with lower prices, but also with a higher vacancy rate and a lower probability of sale. We then get the result that the rate of household formation and the vacancy rate are inversely related, or the Beveridge curve in the housing market.

Why might we care about the Beveridge curve? As I stated earlier the Beveridge curve can be considered a long-run equilibrium relationship. Short-run deviations (46 years) from the Beveridge curve can be interpreted as a measure of oversupply, or disequilibrium. Examining the estimates from the total housing market, irrespective of ownership status, in 2008 the oversupply of the housing stock stood at $0.89 \pm 0.17 \%$ as a percentage of the total housing stock. This compares to the previous peaks of $0.80 \pm 0.26 \%$ in 1974 and $0.37 \pm 0.11 \%$ in the mid to late 1980s. Under this metric the current housing market disequilibrium is similar to the 1974 crisis. However, for the 1974 crisis the rate of household formation was much higher. If we divide the measure of oversupply by the rate of household formation we get a metric of years of oversupply. Under this metric, in 2008 there were $0.995 \pm 0.193$ years of oversupply as compared to $0.285 \pm 0.093$ in 1974 . This implies a substantialy more out of equilibrium housing market in the recent crisis than in the 1973-1974 crisis.

We can allocate oversupply across the owner-occupied and rental markets. The estimates in this paper imply that (1) oversupply shows up much more in the rental market than in the owner-occupied market; (2) oversupply in the rental market is twice as volatile as in the owner-occupied market; and (3) during periods of overall oversupply, such as 1974 , the mid to late 1980s, and the current crisis, oversupply first shows up in the rental market. Interestingly two-thirds of the oversupply in 2007-2008 resided in the rental market as oppposed to the owner-occupied market. The rental market seems to be a sponge that soaks up the oversupply of housing units, and then squeezes the units back out once houses become scarce again. These results suggest that in order to have a full understanding of the adjustments in the housing market, we need to jointly model the rental and the owner-occupied market and understand why oversupply is more likely to show up in the rental market.

Focusing exclusively on the owner-occupied market, using the house price index from the Federal Housing Finance Agency (FHFA), ${ }^{6} 46 \%$ of the biannual movements in oversupply can be explained by real house price movements. A byproduct of the estimation is an estimate of a log-linear trend for FHFA real house prices. Using the estimated trend, if house prices were to fall the same amount below trend as in previous housing downturns

\footnotetext{
${ }^{5}$ Both Topel and Rosen (1988) and DiPasquale and Wheaton (1994) have found that time on the market has a significant influence on housing starts.

${ }^{6}$ This index was previously know as the OFHEO index
} 
$(1975,1983,1995)$ then real house prices will fall a total of $32.0 \%$ relative to trend from peak to trough in the current downturn. As of fourth quarter 2008, prices had already fallen $16.8 \%$, implying an additional fall of $15.1 \% .^{7}$

The observation that almost half of the movements in oversupply in the owner-occupied market can be explained by price movements suggests that at short time horizons, such as six years or less, house price movements drive oversupply. Such a result is consistent with a view of the housing market where, at short time horizons, new construction is too insignificant relative to the stock of housing to affect house prices, enabling deviations of house prices due to demand side shocks or animal spirits. ${ }^{8}$ The same view is argued in the excellent work by Glaeser and Gyourko (2007), and Glaeser, Gyourko and Saiz (2008). As they argue, the inability of supply to pin down prices at short time horizons allows for the formation of bubbles. Depending upon the elasticity of supply these short-run price elasticities can result in an over-accumulation of houses. The estimated results regarding the Beveridge curve relationship in this paper further support their results.

This paper extends the supply side of the model in Glaeser, Gyourko and Saiz (2008) by including the probability of a sale and the vacancy rate. In earlier work, both Topel and Rosen (1988) and DiPasquale and Wheaton (1994) have found that prices and the number of months on the market for new homes sold explain a large part of the time series for housing starts. If we make the assumption that the probability of a sale varies with time on the market, then the empirical results from these papers are consistent with the supply side model in this paper.

The residential vacancy rate has received little attention in the housing supply literature, with the recent exception of Hwang and Quigley (2006). The role of the vacancy rate in the rental housing market has been highlighted in the work of Rosen and Smith (1983) and Gabriel and Nothaft $(1988,2001)$. The paper by Coulson (1999) brings out the idea that builders respond to the probability that they can sell a house by relating housing construction to the stock of unsold new housing units, but it does not include the vacancy rate of existing homes. In the forecasting literature the vacancy rate has played a prominent role going back to 1960s, see the early excellent overview of Fair (1972). Casual observation of the forecasting literature suggests that some forecasters like to use the vacancy rate as a measure of disequilibrium while others compare accumulated housing starts to some normal level typically determined by the rate of household formation. This paper combines the two ideas by making the vacancy rate be a function of the rate of household formation.

\footnotetext{
${ }^{7}$ Note that these price changes are in real terms relative to trend growth, which is estimated at $1.16 \%$ annual growth. Therefore, the actual real fall would be less than the additional $15.1 \%$ depending upon how long it takes prices to fall. Furthermore, the nominal fall would also depend upon the overall inflation rate.

${ }^{8}$ In Peterson (2009) I argue that house prices can deviate from fundamentals by market participants interpreting temporary house price movements as permanent by neglecting the effect of search frictions, or the ease with which a seller can sell a house, on the bargaining process.
} 
The next section covers the data used in the analysis. The subsequent section estimates the Beveridge curve for the housing market. A simple model provides a structural interpretation of the estimates is contained in section 4 . The implications of the model for oversupply are covered in section 5. This section includes the estimates of oversupply and the implications for the allocatin of oversupply across the rental and owner-occupied markets. The penultimate section relates the oversupply in the owner-occupied market to house prices. The last section concludes.

\section{Data}

The source of all of the data is the Census department's quarterly Housing Vacancies (HV) survey. The survey is part of the Current Population Survey (CPS) and is essentially a survey of the housing stock while the CPS is a survey of the people. The housing stock consists of housing units. Each housing unit is classified according to its current use. There are more than ten possible categories, but for this paper each housing unit is classified into one of five categories:

\section{Owner-Occupied}

2. Tenant-Occupied

3. Vacant for sale

4. Vacant for rent

5. Other: Seasonal, Vacation Homes, etc.

For the current analysis, we can discard the last 'Other' component. ${ }^{9}$ The data are not only informative about the housing stock, but also about households, since, by definition a household inhabits a housing unit.

\subsection{Households}

Put households into one of two categories:

- Owners: given by the stock of owner-occupied housing units

- Renters: given by the stock of tenant-occupied housing units

\footnotetext{
${ }^{9}$ Most of the housing units in the 'other' categories are not cyclical, with the exception of 'vacant units held-off the market'. Inclusion of this category would affect the quantitative results of the paper, implying a greater current oversupply of homes, but not the qualitative results. However, I exclude this category from the analysis because the nature of these housing units is not clear-i.e. are they abandoned units that are on their way to being depreciated or units held off the market until the market rebounds? For more see http://housingbeveridge.blogspot. com/2009/04/we-all-want-to-know-when-housing-market.html.
} 


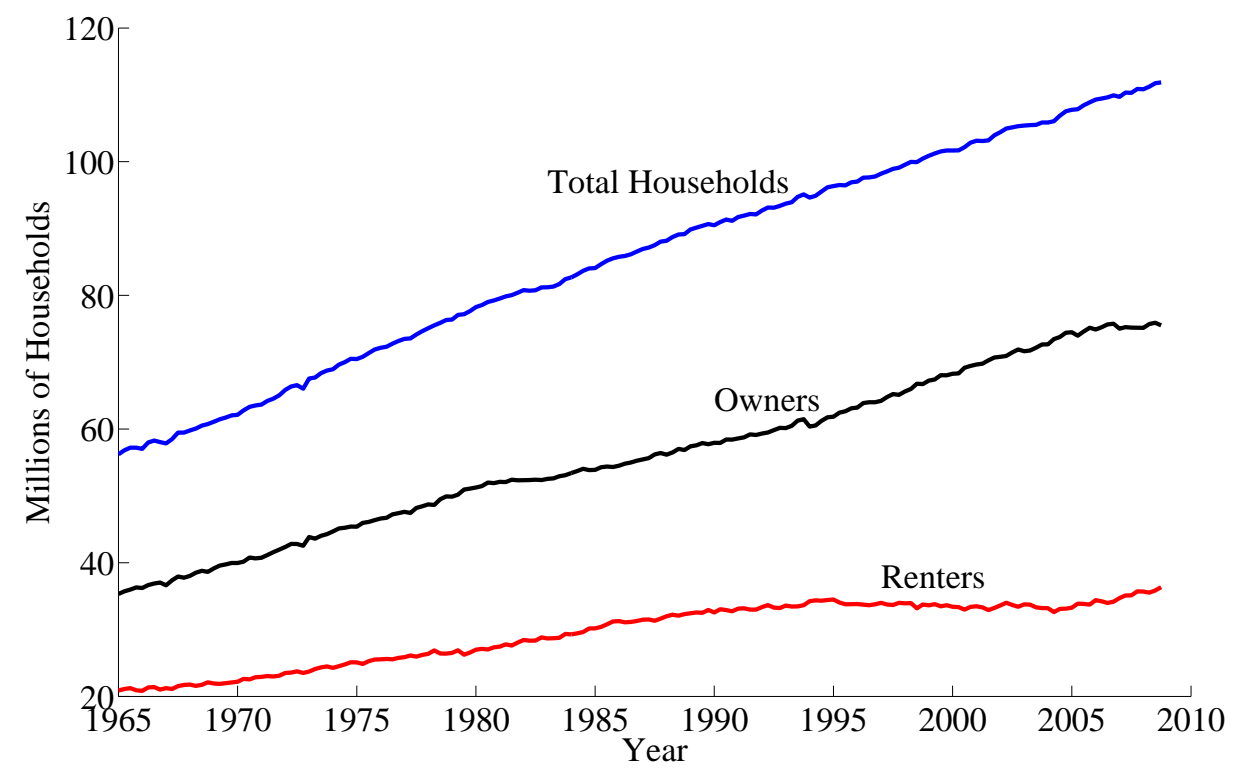

Figure 1: Households by tenure status, quarterly Source: Census CPS/HV.

Denote the number of owners at time $t$ as $\mu_{t}^{O}$ and the number of renters at time $t$ as $\mu_{t}^{R}$. Let $\mu_{t}^{T}$ refer to 'total households' at $t$, irrespective of ownernship, as

$$
\text { total households }=\text { owners }+ \text { renters. }
$$

or $\mu_{t}^{T}=\mu_{t}^{O}+\mu_{t}^{R}$.

Figure 1 plots the time series for owners, renters, and total households. ${ }^{10}$ In general all three series trend up, with one striking exception: starting in 1995 the numbers of renters is flat, actually falling slightly, while total households and owners continue increasing. In fact, there were fewer renters in 2005, 34.4 million, than 1995, 33.3 million. This is despite the fact that total households increased by 11.5 million. Such a large shift from renting to owning is most likely at the heart of the housing bubble.

The demand for new housing stems from the growth rate of households. The very subtle movements in the level of households in figure 1 result in an excessively noisy series for quarterly growth rates of households. Instead, figure plots 2 the annualized biannual growth rates in owner, renters and total households. ${ }^{11}$

\footnotetext{
${ }^{10}$ I have modified the published series due to rebenchmarking associated with the decennial census, generating a new series for levels by working backwards from 2008 using the growth rates. The details are in the appendix.

${ }^{11}$ The biannual observation is used because it generates a series that seems relatively free from noise. Even at the annual frequency there is evidence of an MA component in the levels that creates excess
} 


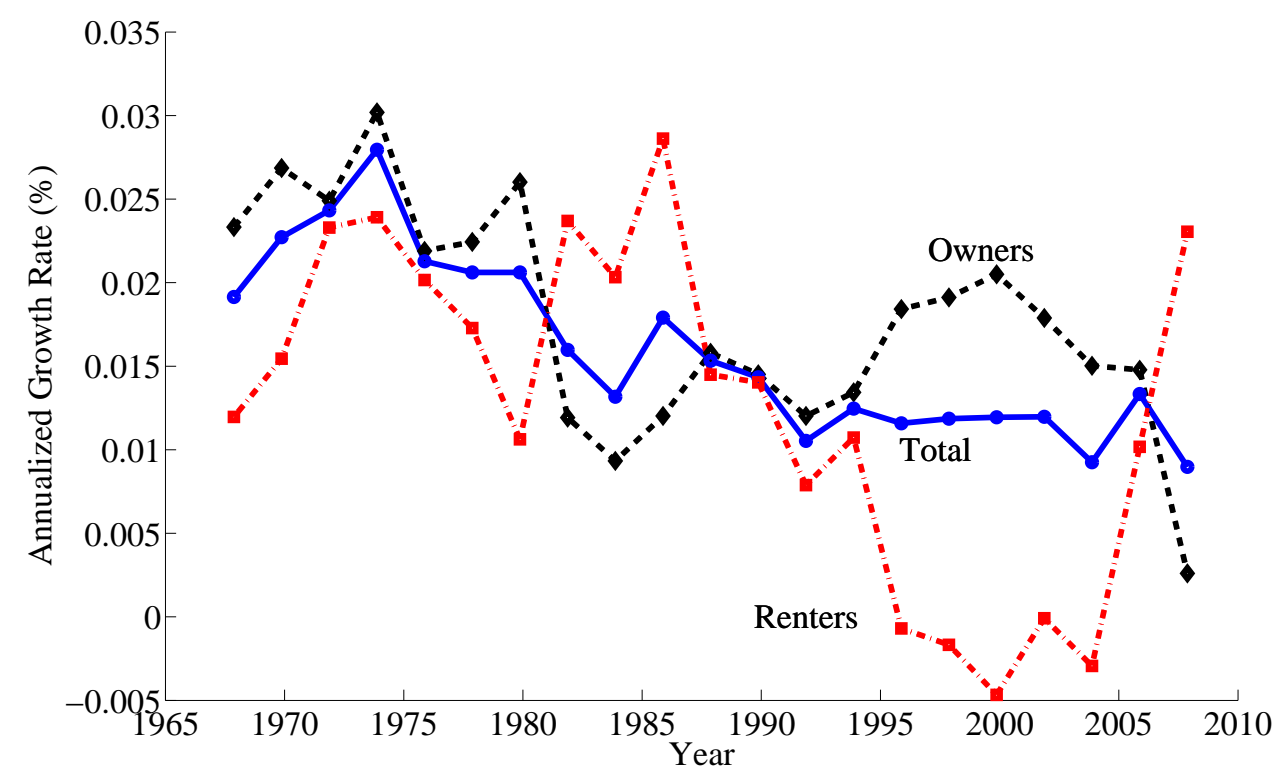

Figure 2: Annualized biannual growth rates of households by tenure status, Source: Census CPS/HV.

Examining figure 2 we see large swings in the growth rates of owners versus renters. In fact there is striking evidence that business cycles are to a large part related to changes in the growth rate of owners. Every recession is preceded by a slow down in the growth rate of owners. Except for the 1990-1991 recession, the slowdown in the growth of owners is related to an increase in the growth of renters. Especially striking are the large swings before the deep recession in the early 1980s and today. The current swing from owning to renting is quite frightening. Even more startling is that the switch from owning to renting was quite evident in the 2005-2006 observation.

The baby-boom makes its mark in figure 2. We see clearly the peak in the growth of total households in the mid 1970s, followed by a steady decline to the current growth rate of roughly $1 \%$ per year. The growth rate of total households is also cyclical, with a slowdown in all recessions, except for the 2000 recession-a recession that we now know was not a recession for the housing market. A slowdown in household formation from the current crisis seems almost assured given the large increase in unemployment we have seen.

The growth rate of households is the 'demand' side of the Beveridge curve. The other side is the supply side, which we turn to next.

volatility in the growth rates. To be agnostic, I use the raw biannaul data rather than use a state-space method to estimate a trend and a cyclical component. 


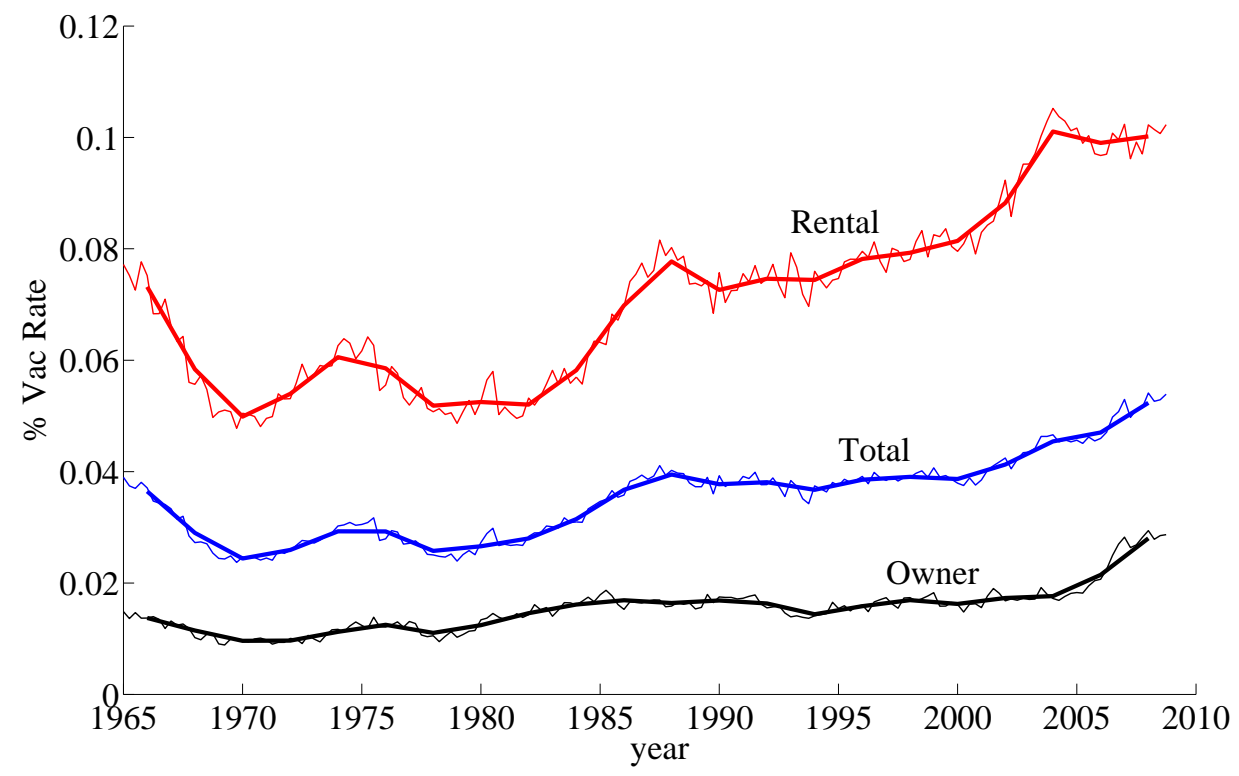

Figure 3: Vacancy rates by type of market: owner-occupied, rental, and total irrespective of ownership status. Both biannual (thick lines) and quarterly (thin lines) are shown; Source: Census CPS/HV.

\subsection{Vacancy Rates}

Besides informing us about households, the Census data also informs us about housing units. Define the following aggregates of the housing stock:

- Owner Stock $\left(\mu_{t}^{O S}\right)$ : Owner-Occupied homes plus vacant homes for for sale,

- Rental Stock $\left(\mu_{t}^{R S}\right)$ : Tenant-Occupied homes plus vacant homes for rent,

- Total Stock $\left(\mu_{t}^{T S}\right)$ : Owner Stock plus Rental Stock,

where $\mu_{t}^{i S}$ denotes the stock of type $i$ at time $t$ for $i \in\{O, R, T\}$. We are after the vacancy rate. There are three markets for which we can consider a vacancy rate: the owner-occupied market $(O)$, the rental market $(R)$, and the total market $(T)$ irrespective of ownership status. Let $v_{t}^{i}$ denote the vacancy rate at time $t$, in market $i \in\{O, R, T\}$. The formula for $v_{t}^{i}$ is given by

$$
v_{t}^{i}=1-\frac{\mu_{t}^{i}}{\mu_{t}^{i S}} .
$$

The calculated vacancy rates are plotted in figure 3 , where there is a biannual series along with the raw quarterly series. 
As expected the vacancy rate is higher in the rental market than in the owner-occupied market. This is not included in the paper, but the movements in all three series are almost identical, even in magnitude, after taking logs. The vacancy rates are cyclical, and in general, they have all been rising since 1980. Currently, all three vacancy rates are roughly at their all time highs, although the rental vacancy may have beeen a bit higher in $2004 .^{12}$ Also of note is the surge in the rental vacancy rate starting about 2002-the oversupply was already showing up then.

With the data laid out, we can now turn our attention to comparing the household growth rates to the vacancy rates. We will do this for all three markets.

\section{Beveridge Curve in the Housing Market}

As discussed earlier, the Beveridge curve in the labor market is the negative relationship between the demand for labor, given by job vacancies, and the level of underutilization of labor, the unemployment rate. Here we examine whether such a negative relationship exists in the housing market. The demand for housing originates from the growth rate of households. The underutilization of housing is given by the vacancy rate. We can think of three different housing markets: the owner-occupied market, the rental market, and the total market irrespective of ownership. ${ }^{13}$

Figures 4 through 6 plot the Beveridge curves for all three markets. There is a clear negative relationship between the vacancy rate and the growth rate of households in all three markets. We can capture the relationship in the simple equation

$$
v_{t}^{i}=\hat{\Omega}^{i}+\hat{\alpha}^{i} \gamma_{t}^{i}+\varepsilon_{t}^{i}
$$

where $\gamma_{t}^{i}$ is the annualized growth rate of households of type $i$; $\varepsilon_{t}^{i}$ is a shock to market $i$; and $\hat{\Omega}^{i}$ and $\hat{\alpha}^{i}$ are parameters for market $i$. To quantify the relationship, for each market $i \in\{T, O, R\}$, a simple OLS regression of the vacancy rate on the growth rate and a constant is performed. The results are in table 1.

For all three markets the coefficient on the growth rate of households is negative. For the owner and total market the adjusted R-squared is over 0.6 and the coefficient on the growth rate of households is significant at the $99 \%$ level. The results in the rental market are weaker, with an adjusted R-squared of only 0.215 , but still quite significant, with the p-value that $\hat{\alpha}^{R}=0$ being 0.0197 . The fit for each market using the entire sample is represented in figures 4 through 6 by the solid line. The regression analysis supports the existence of a Beveridge curve for all three markets.

A striking feature in all three markets is the location of the latest observation, noted by '07-08' in each figure. In the owner-occupied market the most current observation is quite

\footnotetext{
${ }^{12}$ When I first started this project, the falling rental vacancy rate and rising owner-occupied vacancy rate after 2004 is what caught my eye. Unfortunately, both of them are now rising, which does not bode well for the housing market.

${ }^{13}$ Note that these are not three independent observations.
} 


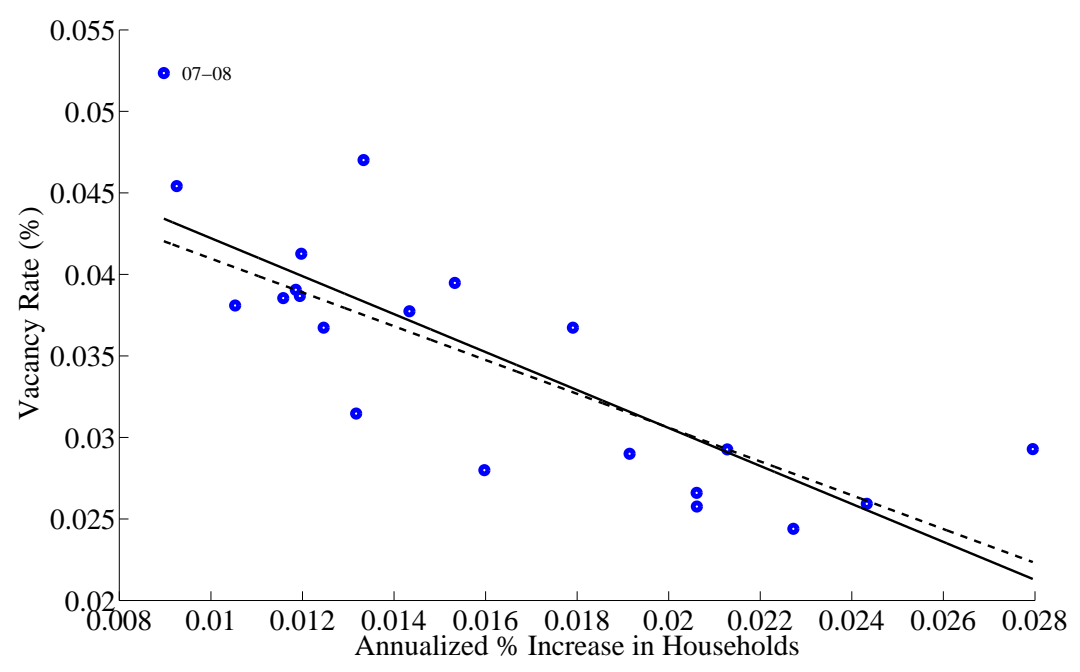

Figure 4: Beveridge Curve for total market irrespective of ownership status. Solid line denotes fit using the whole sample. Dashed line denotes fit when 07-08 observation is removed. Biannual Data.

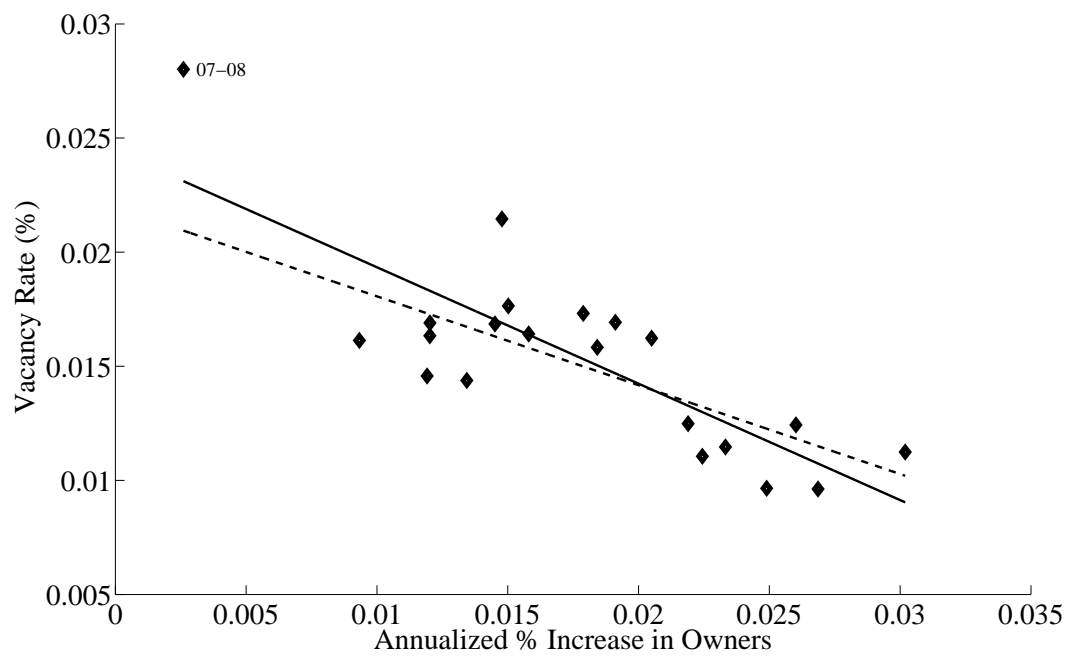

Figure 5: Beveridge Curve for owner-occupied market. Solid line denotes fit using the whole sample. Dashed line denotes fit when 07-08 observation is removed. Biannual Data. 


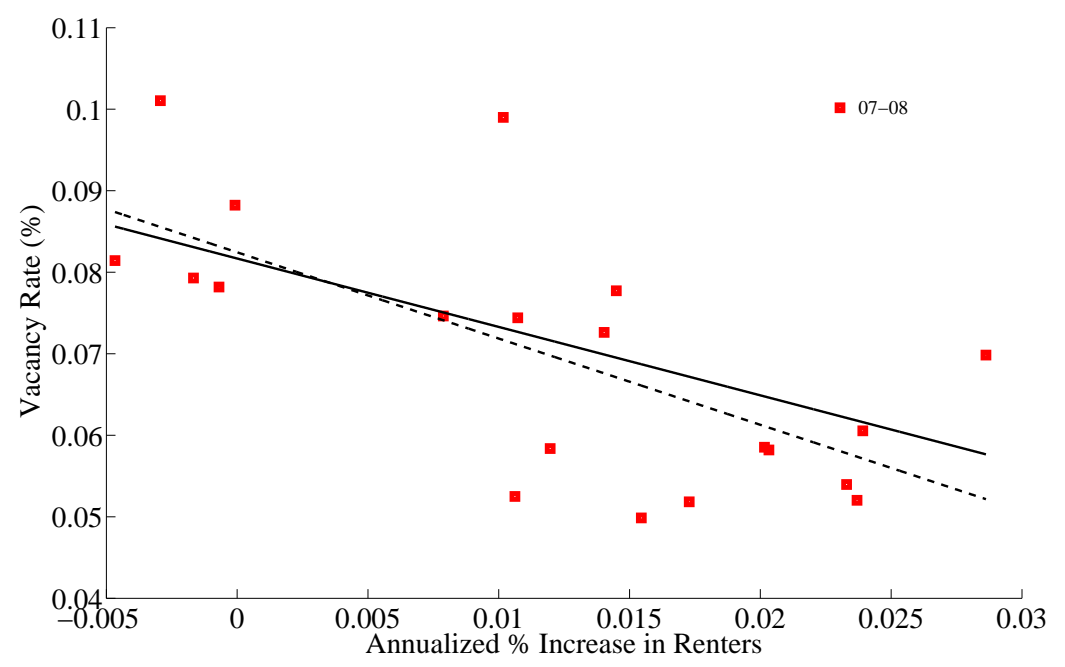

Figure 6: Beveridge Curve for rental market. Solid line denotes fit using the whole sample. Dashed line denotes fit when 07-08 observation is removed. Biannual Data.

\begin{tabular}{|l|c|c|c|}
\hline Market $i$ & Total & Owner & Rental \\
\hline$\hat{\Omega}^{i}:$ Constant & 0.0539 & 0.0244 & 0.0817 \\
$($ std $)$ & $(0.0033)$ & $(0.0016)$ & $(0.0053)$ \\
\hline$\hat{\alpha}^{i}=0:$ Growth Rate of Households & -1.1644 & -0.5101 & -0.8393 \\
$($ std $)$ & $(0.1983)$ & $(0.0847)$ & $(0.3294)$ \\
\hline$\hat{\alpha}^{i}$ p-value & 0.0000 & 0.0000 & 0.0197 \\
\hline $\mathrm{N}$ & 21 & 21 & 21 \\
\hline $\bar{R}^{2}$ & 0.6260 & 0.6381 & 0.2154 \\
\hline
\end{tabular}

Table 1: Results of OLS regression for Beveridge curve relationship in figures 4 - 6; Full Sample. Dependent variable: vacancy rate.

\begin{tabular}{|l|c|c|c|}
\hline Market $i$ & Total & Owner & Rental \\
\hline$\hat{\Omega}^{i}:$ Constant & 0.0513 & 0.0220 & 0.0824 \\
$($ std $)$ & $(0.0032)$ & $(0.0017)$ & $(0.0042)$ \\
\hline$\hat{\alpha}^{i}:$ Growth Rate of Households & -1.0370 & -0.3893 & -1.0582 \\
$($ std $)$ & $(0.1890)$ & $(0.0862)$ & $(0.2730)$ \\
\hline$\hat{\alpha}^{i}=0$ p-value & 0.0000 & 0.0003 & 0.0011 \\
\hline $\mathrm{N}$ & 20 & 20 & 20 \\
\hline $\bar{R}^{2}$ & 0.6051 & 0.5053 & 0.4247 \\
\hline
\end{tabular}

Table 2: Results of OLS regression for Beveridge curve relationship in figures 4 - 6, Last observation (2007-2008) removed. Dependent variable: vacancy rate. 
far removed from the rest of the observations. However, it is consistent with the observed Beveridge curve: the currently high vacancy rate is consistent with the currently low growth rate of owners. In the rental market the '07-'08 observation is quite far from the estimated relationship for the entire sample, denoted by the solid line in figure 6 . The combination of a high rental vacancy rate and high growth rate of renters is unprecendented.

In order to check the sensitivity of the results to the outlying '07-'08 observations, the OLS regressions were redone for all three markets with the '07-'08 observation removed. The results are in table 2, and the fit is denoted in figures 4 through 6 by the dashed lines. The results for the total market are little changed from table 2. Turning to the owner-occupied market, the adjusted R-squared falls to 0.51, and the estimate for $\hat{\alpha}^{O}$ rises (becoming less negative), however, it is still significantly different from zero at the $99 \%$ signficance level. Shifting to the rental market, removing the last observation greatly increases the fit, raising the adjusted R-squared from 0.22 to 0.42 . This results in $\hat{\alpha}^{R}$ being significantly different from zero at the $99 \%$ level. We can safely say that the existence of a Beveridge curve is not sensitive to the latest observation. Later we will use the estimated Beveridge curve relationship to make a quantitative statement regarding the '07-'08 observations.

To summarize, there is strong evidence of a negative relationship between residential vacancy rates and the growth rates of households. I denote this negative relationship the Beveridge Curve of the Housing Market. The Beveridge curve exists in the owner-occupied market, the rental market, and the total housing market irrespective of ownership status. To provide a deeper understanding of the Beveridge curve, the next section develops a structural relationship between a residential vacancy rate and the growth rate of households.

\section{Strucutural Interpretation}

This section sketches out an informal model to explain the Beveridge curve. Potentially many explanations can generate the negative relationship between household formation and the residential vacancy rate. A logicial route to explore is the reaction of builders, the supply side, to changes in household formation.

To model the decisions of builders assume that the cost, $c$, to produce a new house depends upon the growth rate of the housing stock, $\eta$. Formally, let the cost to produce a home be given by

$$
c(\eta)=\bar{c}+\hat{c} \eta
$$

where $\bar{c}>0$ and $\hat{c}>0$. Such a cost function is assumed in Glaeser, Gyourko and Saiz (2008). Assume that the effective expected real return to building a new house depends upon two factors: ${ }^{14}$

\footnotetext{
${ }^{14}$ These two factors are consistent with the empirical work in Topel and Rosen (1988) and DiPasquale and Wheaton (1994) where prices and time on the the market explain a large part of the movements in
} 
1. the expected sales price, $p$, and

2. the probability that the house will be sold in a given time period, $s$, such as a month.

Further, assume that the effective expected real return is simply the product of the two:

$$
\text { expected return }=s p
$$

Last, assume that $s$ depends inversely on the vacancy rate, $v$. Write

$$
s=s(v) \quad \text { where } s^{\prime}(v)<0 .
$$

A negative relationship between the vacancy rate and the expected sales rate is quite intuitive. Holding the number of buyers fixed, more vacant homes would imply that buyers have more homes to choose from, lowering the probability that any individual new house is sold. ${ }^{15}$ The expected profit, $\pi$, for building a house is given by

$$
\pi=s(v) p-\bar{c}-\hat{c} \eta
$$

Thus, expected profits are decreasing in $v$ and $\eta$ and increasing in the price.

To close the model, differentiate between a short-run ${ }^{16}$ equilibrium and a long-run equilibrium. In the long-run prices are pinned down by free entry in construction, while in the short-run deviations of prices from the supply condition are allowed. Formally, in the short run, the following three conditions hold:

1. Free-Entry There are an infinite number of builders, so that free-entry drives expected profits to zero:

$$
\bar{c}+\hat{c} \eta=s(v) p .
$$

2. Stationarity The vacancy rate is constant. For this to happen, the growth rate of the housing stock, $\eta$, must equal the growth rate of households, $\gamma$, or ${ }^{17}$

$$
\eta=\gamma
$$

3. Prices Assume that prices can be written as:

$$
p=\left(1+\varepsilon^{p}\right) p(v) \quad \text { where } p^{\prime}(v)<0 .
$$

housing starts.

${ }^{15}$ Certainly such an assumption may not be the results of a more general model, particularly with an endogenous supply of existing homes for sale. The model here is simply meant as suggestive. Currently the author is working on putting this framework into a general equilibrium search and matching model of the housing market.

${ }^{16}$ The concept of short-run is driven by the data, so that every observation of the biannual data is treated as an observation of a short-run equilibrium.

${ }^{17}$ This condition roughly holds. In the biannual data the correlation between $\gamma$ and $\eta$ is 0.9889 in the owner-occupied market and 0.9376 in the rental market. 
The $\varepsilon^{p}$ term represents a deviation from the long-run equilibrium price given by $p(v)$. This form allows for the flexibility of short-run deviations of the price, while maintaining that in the long-run prices are ultimately driven by supply so that $\varepsilon^{p}$ equals zero. The assumption that $p^{\prime}(v)<0$ generally holds in search and matching models, see Wheaton (1990).

Combining equations (4) to (6) we arrive at the following short-run stationary equilibrium condition as depending upon the exogenous growth rate of households, $\gamma$, and the short-run deviation in prices, $\varepsilon_{p}$ :

$$
\bar{c}+\hat{c} \gamma=\left(1+\varepsilon_{p}\right) s(v) p(v) .
$$

Take a first-order Taylor series approximation around $\gamma=\bar{\gamma}, v=\bar{v}$ and $\varepsilon_{p}=0$ to get

$$
\bar{c}+\hat{c} \gamma=s(\bar{v}) p(\bar{v})+s(\bar{v}) p(\bar{v}) \varepsilon^{p}+\left[s^{\prime}(\bar{v}) p(\bar{v})+s(\bar{v}) p^{\prime}(\bar{v})\right](v-\bar{v}) .
$$

Define the solution for $v$ from equation (8) as the 'short-run' vacancy rate, $v_{S R}$, given by

$$
v_{S R}=\Omega+\alpha \gamma+\rho \varepsilon^{p}
$$

where

$$
\begin{gathered}
\Omega=\bar{v}-\frac{s(\bar{v}) p(\bar{v})-\bar{c}}{\left[s^{\prime}(\bar{v}) p(\bar{v})+s(\bar{v}) p^{\prime}(\bar{v})\right]}, \\
\alpha=\frac{\hat{c}}{\left[s^{\prime}(\bar{v}) p(\bar{v})+s(\bar{v}) p^{\prime}(\bar{v})\right]},
\end{gathered}
$$

and

$$
\rho=-\frac{s(\bar{v}) p(\bar{v})}{\left[s^{\prime}(\bar{v}) p(\bar{v})+s(\bar{v}) p^{\prime}(\bar{v})\right]} .
$$

Let the 'long-run' be such that prices are determined by supply so that $\varepsilon_{p}=0$. Using this definition of the long-run, the long-run vacancy rate, $v_{L R}$, is given by

$$
v_{L R}=\Omega+\alpha \gamma
$$

By assumption, $\left[s^{\prime}(\bar{v}) p(\bar{v})+s(\bar{v}) p^{\prime}(\bar{v})\right]<0$, which implies that $\alpha<0$. Therefore, equation (10) denotes a negative relationship between the vacancy rate and the growth rate of households, or the Beveridge curve relationship. In the short-run, deviations from the Beveridge curve are driven by deviations of prices from their long-run level, so that the vacancy rate is given by equation (9).

\subsection{Interpretation}

To understand the model, suppose that the rate of household formation falls. The growth in the housing stock that is needed to satisfy demand falls. By assumption, the cost to produce one new home is decreasing in the growth rate of the housing stock. Therefore, the average cost to produce the new homes to meet the growing population falls. 


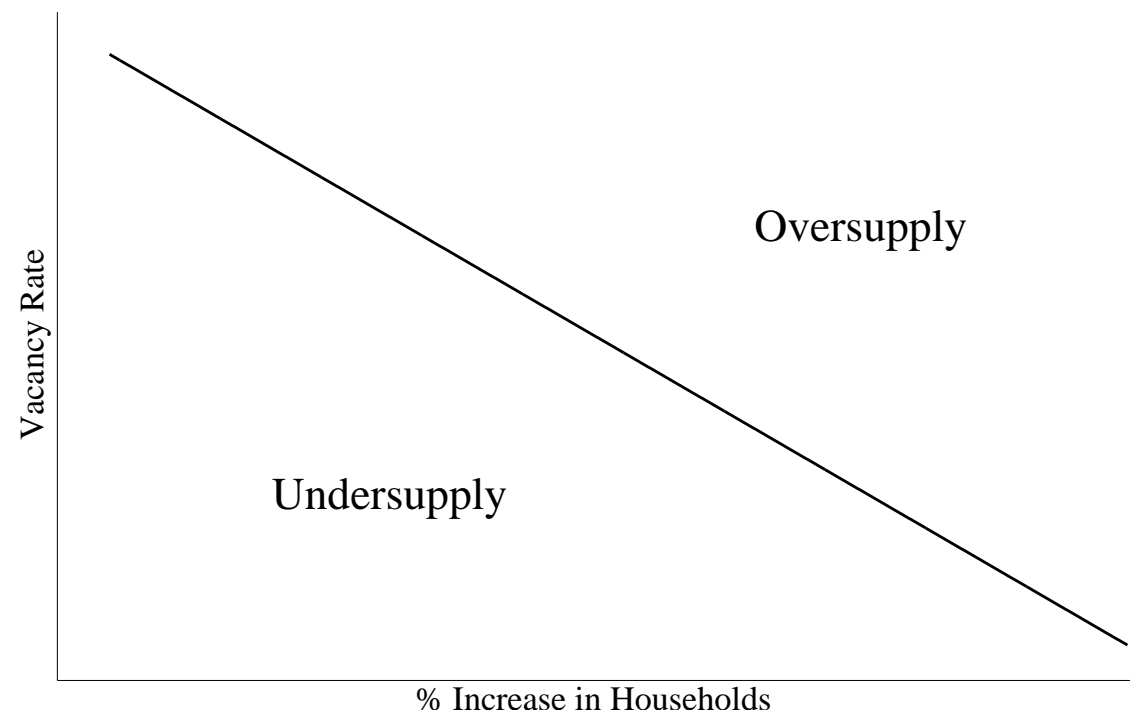

Figure 7: Structural interpretation of Beveridge curve.

There are two adjustments to clear the market when the rate of household formation falls. The first is the standard adjustment that house prices fall since the costs of production have fallen. The second adjustment relates to the vacancy rate. When the cost to produce a home is low, a builder may want to produce more homes. This is not modelled, but one potential reason is that a builder may want to add variety. This lowers the probability of an individual house selling, but it raises the probability that an individual builder may sell one house. In essence, builders respond to the lower costs by raising supply. The higher supply shows up in a higher vacancy rate. At some point in time the vacancy rate rises enough to stem more production and the market returns to equilibrium. Therefore, we get the following result: A lower growth rate of households lowers the costs of production to meet demand, leading to lower prices and higher vacancy rates. Thus, the Beveridge Curve.

Figure 7, illustrates how we should think of the long-run relationship in the Beveridge curve. When the current market condition is to the northeast, there is an oversupply of homes. The vacancy rate is too high relative to the rate of household formation. High prices could drive the market into this area. When the current market condition is to the southwest there is an undersupply of housing units. The vacancy rate is too low relative to the rate of household formation. Given an estimate of the Beveridge curve we can make a statement about the current over/under supply in the housing market. 


\section{Oversupply}

The model of the previous section argues that the Beveridge curve represents a long-run equilibrium determining the long-run vacancy rate given by equation (10). In the shortrun, deviations of prices from the long-run equilibrium can lead to short-run deviations of the vacancy rate, given by equation 9 . Denote the difference between the short-run vacancy rate and the long-run vacancy rate as the oversupply of housing units, $O S$, given by

$$
O S=v_{S R}-v_{L R}
$$

The units for oversupply are in a percentage of the total housing stock. As an alternative measurement of oversupply, divide the $O S$ measure by the annualized rate of household growth, $\gamma$, to arrive at a years of oversupply measure, $Y O S$, given by

$$
Y O S=\frac{O S}{\gamma}
$$

The years of oversupply measure is similar to the concept of months of supply commonly used to measure inventories. The $Y O S$ measure denotes how many years it would take for the oversupply to disappear if there were no more construction and household formation continued at its same rate. Note that this is slightly different from the months of supply used for inventories, which denotes the months of sales so that inventories go to zero. Here the measure denotes the years for the oversupply to go to zero-there will still be vacant housing units equal to the long-run vacancy rate if the oversupply goes to zero.

\subsection{Total Market}

We can use our estimated Beveridge curve to give us an estimate of oversupply for the total housing market, irrespective of ownership status. The idea is to interpret the estimated Beveridge curve as the long-run and the current vacancy rate as the short-run. Therefore, define the estimated oversupply in the total (T) housing market at time $t$ as

$$
O S_{t}^{T}=v_{t}^{T}-\left[\hat{\Omega}^{T}+\hat{\alpha}^{T} \gamma_{t}^{T}\right]
$$

The estimated parameters, $\hat{\Omega}^{T}$ and $\hat{\alpha}^{T}$ come from table 1 , and $v_{t}^{T}$ and $\gamma_{t}^{T}$ are the realizations of the data. The estimated time series is plotted in figure 8 along with one standard deviation error bands. ${ }^{18}$ We can see that there have been three periods of oversupply since 1967: 1974 , peaking at $0.80 \% \pm 0.26 \%$ of the total housing stock; the late $1980 \mathrm{~s}$, peaking at $0.37 \% \pm 0.11 \%$; and the last four years, 2005-2008, with the oversupply sitting at $0.89 \% \pm 0.17 \%$. Therefore, the current oversupply is at an all-time high by this measure, but not statistically significnantly greater than the oversupply in 1974 . However, the current oversupply has endured longer than the oversupply of 1974.

\footnotetext{
${ }^{18}$ The one standard deviation is from the uncertainty in $\hat{\alpha}^{T}$ and $\hat{\Omega}^{T}$.
} 


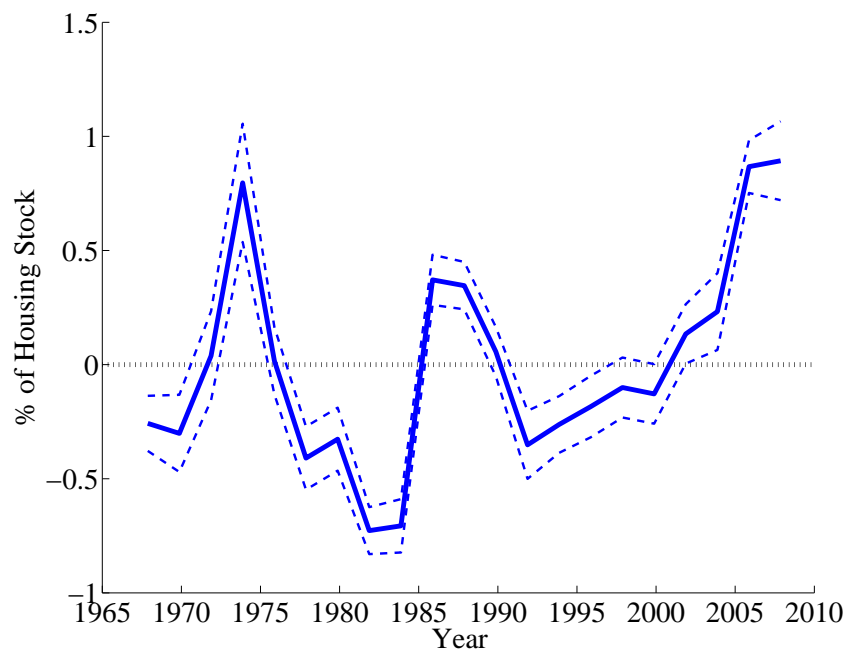

Figure 8: Estimated oversupply of housing units as a $\%$ of the total housing stock for the total housing market irrespective of ownership status. The dashed lines represent one standard deviation.

One reason for the endurance of the current oversupply relative to 1974 is that the rate of household formation was much higher in 1974 than today. To adjust for this, the years of oversupply measure, defined as

$$
Y O S_{t}^{T}=\frac{O S_{t}^{T}}{\gamma_{t}^{T}}
$$

may give a better indication of the magnitude of the oversupply. Figure 9 plots the time series for years of oversupply. By this measure the current amount of oversupply is unprecendented. The 1973-1974 and 1987-1988 years of oversupply peaked out at $0.285 \pm$ 0.093 and $0.226 \pm 0.068$, respectively. The latest two observations, 2005-2006 and 20072008 have been $0.651 \pm 0.087$ and $0.995 \pm 0.193$, respectively. Part of the rise in the last two years is due to a fall in the growth rate of households. Regardless, using the metric of years of oversupply, the disequilibrium in the housing market is truly exceptional.

Before moving on to the oversupply in the rental and owner-occupied markets, let me comment about the oversupply measures estimated in this section. The value to using these measures is that they give us a measure of oversupply relative to a changing longrun equilibrium. A common measure of oversupply could simply be the vacancy rate. However, this would be misleading, because, as this paper has been stressing, the vacancy rate moves with the rate of household formation. If we were to use the raw vacancy rate, as in figure 3, we would come to the conclusion that there was a larger oversupply of homes in 1993 than in 1974. This seems at odds with the perceptions of market participants who 


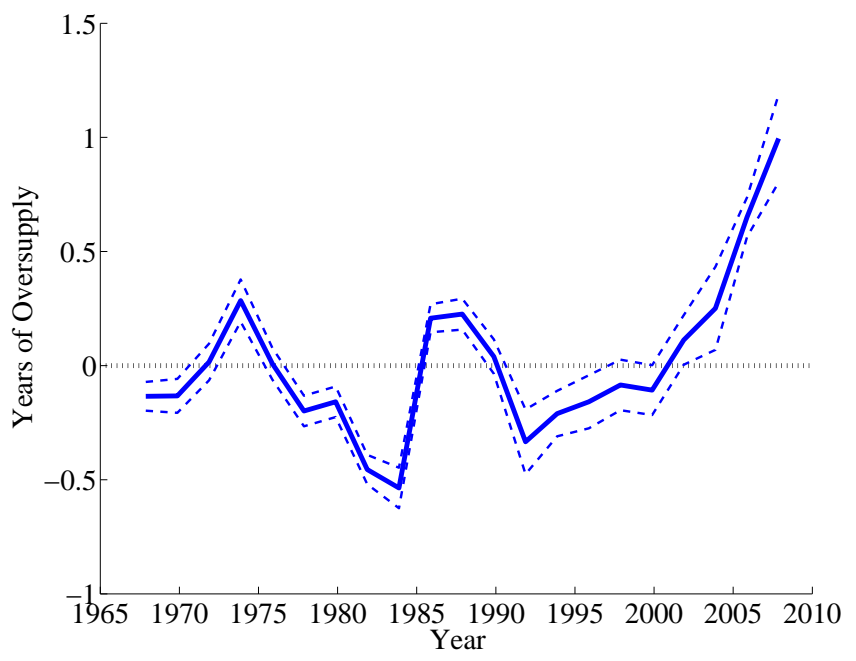

Figure 9: Estimated oversupply of housing units in years of household growth for the total housing market irrespective of ownership status. The dashed lines represent one standard deviation.

viewed the oversupply in 1974 as such a problem as to generate legislation to subsidize home purchases. In contrast, the time series for oversupply in either figure 8 or 9 are generally in line with what people consider as periods of oversupply.

Another popular approach to compute oversupply compares the growth of the housing stock from construction data to the average growth rate of households or the population. Such a comparison is implicit in the model here, since in equilibrium the growth of households equals the growth of the housing stock. However, the model here also examines the current vacancy rate. In this way, the model of this paper combines the idea that there is a long-run equilibrium vacancy rate with the idea that growth in the housing stock should roughly equal growth in households.

\subsection{Rental Market and Owner-Occupied Market}

In this section the oversupply in the rental and owner-occupied markets is estimated. This allows us to understand how the oversuppply in the overall market is allocated across the two markets. This helps us think about how we should model the relationship between the two markets and address how the concept of ownership matters for the deeper housing market.

Define oversupply in market $i$ at time $t$, for $i \in\{\operatorname{Owner}(O), \operatorname{Rental}(R)\}$ as

$$
O S_{t}^{i}=\left[v_{t}^{i}-\left(\hat{\Omega}^{i}+\hat{\alpha}^{i} \gamma_{t}^{i}\right)\right] \frac{\mu_{t}^{i S}}{\mu_{t}^{T S}}
$$


The ratio $\mu_{t}^{i S} / \mu_{t}^{T S}$ denotes the percentage of the total housing stock that is in market $i$. By multiplying the oversupply term by this measure it puts oversupply in units of a $\%$ of total housing units. This allows us to compare the magnitude of oversupply in the owner market to the rental market. Likewise, define years of oversupply in market $i$ at $t$ as

$$
Y O S_{t}^{i}=\frac{O S_{t}^{i}}{\gamma_{t}^{T}}
$$

Here, we divide oversupply by the growth rate of total households, $\gamma_{t}^{T}$, as opposed to the growth rate of households in market $i, \gamma_{t}^{i}$. Once again, this allows us to compare the oversupply in the rental market to the owner-occupied market. ${ }^{19}$

There is one caveat: there is no restriction in the estimation ensuring that the oversupply in the owner-occupied and rental market sum to the oversupply in the total market. Therefore, also consider a second measurement of oversupply in the rental market as simply the difference between the oversupply in the total market and the oversupply in the owner-occupied market. Refer to this market as the 'restricted rental market' (RR). The oversupply in market $R R$ is given by

$$
O S_{t}^{R R}=O S_{t}^{T}-O S_{t}^{O}
$$

The years of oversupply for the restricted rental market is simply given by

$$
Y O S_{t}^{R R}=\frac{O S_{t}^{R R}}{\gamma_{t}^{T}}
$$

Figure 10 plots both the independent estimation of the rental market and the estimation for the restricted rental market using the years of oversupply measure. ${ }^{20}$ Both measures have a similar time series, with one exception. The independent measurement seems to have a trend, slowly growing. A slight clockwise rotation to the independent estimation would make the two series almost equivalent. This suggests some ongoing structural change in the rental market. Therefore, for the rest of the paper we will use the restricted rental market to make comparisons to the owner-occupied market.

Using the restricted rental market, we can now compare the oversupply in the owneroccupied market to the rental market. Figure 11 plots oversupply for both markets. There are two interesting features in figure 11:

1. Oversupply in the rental market is more than twice as volatile as in the owneroccupied market. Specifically the standard deviation of oversupply is $0.35 \%$ in the rental market versus $0.16 \%$ in the owner-occupied market.

\footnotetext{
${ }^{19}$ Dividing by the growth rate of households in market $i$ also leads to very large swings in a years of oversupply measure. This is especially so in the rental market where the growth rate of renters goes negative.

${ }^{20}$ The estimates from the whole sample in table 1 are used for the restricted rental market, while the estimates excluding the last observation are used for the independent rental market estimate. Using the full sample for the independent estimation does not affect the general story from figure 10 that there is a trend in oversupply in the independent estimate for the rental market.
} 


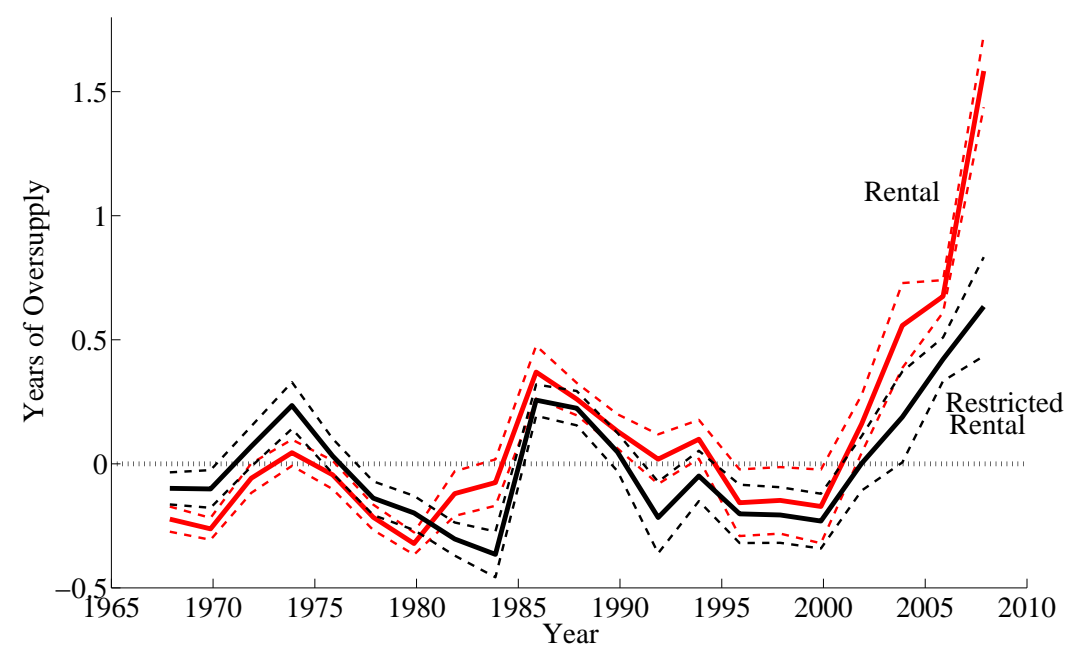

Figure 10: Years of Oversupply in the Rental Market 'Rental' refers to the independent estimate of the rental market. 'Restricted Rental' refers to the estimate of the rental market as the difference between oversupply in the total market and the owner-occupied market.

2. In all three episodes of oversupply (early 1970s, mid 1980s and the current crisis) the oversupply first shows up in the rental market.

Both of these observations suggest that the rental market is key to understanding the boom-bust properties of the housing market. There is more discussion on this issue below.

Turning to the current housing market, figure 12 plots the years of oversupply for both markets. The oversupply in the rental market has become unprecendented. In fact by 2005-2006 there was a clear oversupply in the rental market that was greater than the owner-occupied market. This oversupply was (and still is) greater than the oversupply in 1974 and the mid to late 1980s-both periods that were related with a housing bust. By 2006 the data were clearly pointing to the potential of a housing bust. Comparing the latest estimates, 2007-2008, in the owner-occupied market there are $0.362 \pm 0.156$ years of oversupply, while in the rental market there are $0.634 \pm 0.200$ years of oversupply. These estimates state that two-thirds of the current glut of housing units reside in the rental market, not in the owner-occupied market. However, we should remark that in the past housing gluts (1974 and mid 1980s) almost all of the excess supply was in the rental market.

Figures 11 and 12 suggest that to understand the boom-bust properties of the housing market, we need to understand the mechanism that causes so much of the surplus of housing to end up in the rental market. There are potentially many reasons. One reason could be that rental housing is primarily in large, multiple units structures. Under this 


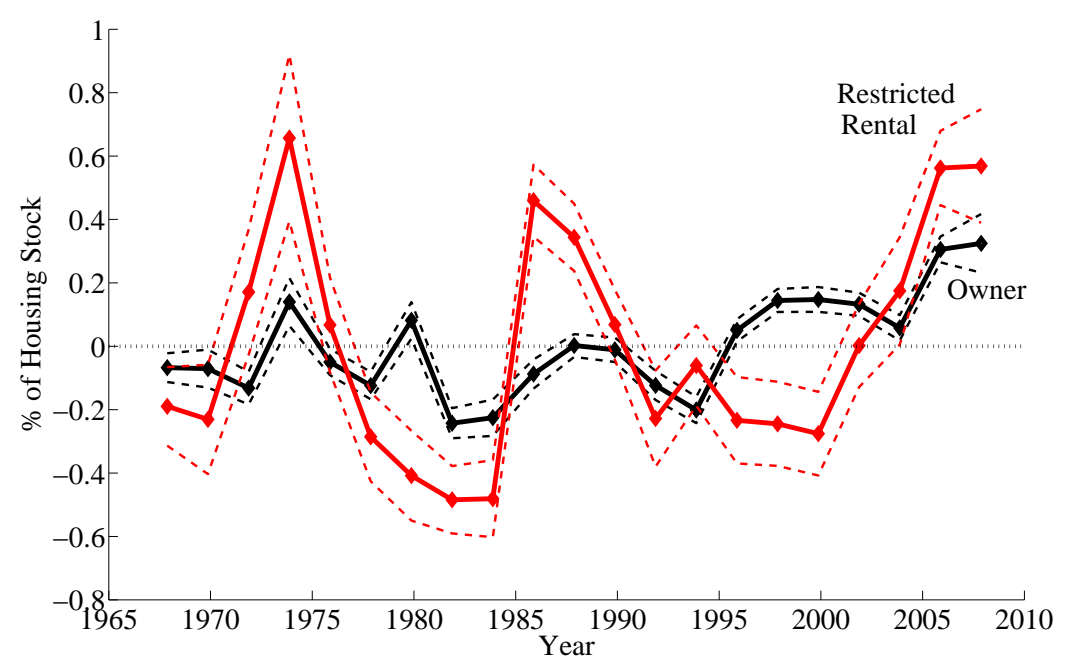

Figure 11: Oversupply in the Owner-Occupied and Rental Market.

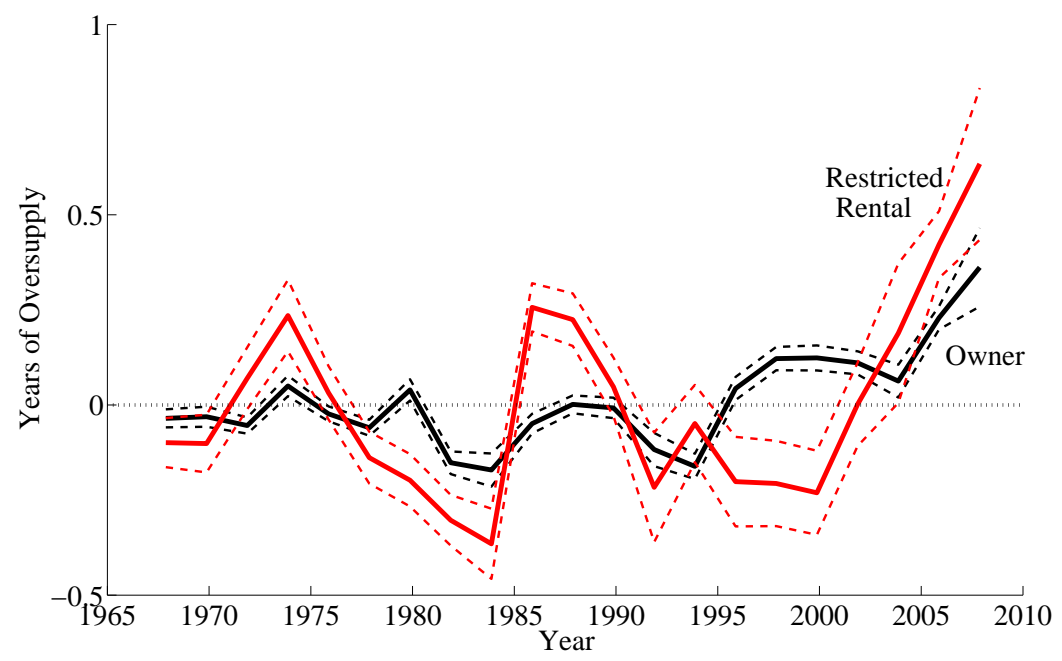

Figure 12: Years of Oversupply in the Owner-Occupied and Rental Market. 
hypothesis, the size of investment in rental properties could lead to larger swings in supply.

Another hypothesis is that housing units move across markets throughout the cycle. This would imply that at the end of the housing cycle, as over-production is taking place for new houses, that a portion of the existing owner-occupied housing stock is being reallocated to the rental housing market. This implies that one of the relevant margins for adjustment in the owner-occpied housing market is not just production, but, at the margin, it is the decision to reallocate a housing unit from the owner-occupied market to the rental market. The existence of such a margin is important for policy to try and stabilize the housing market. If the relevant margin to restore equilibrium in the housing market is to reallocate housing units, and households, across the rental and owner-occupied markets, then foreclosure would seem to be a mechanism to achieve this. A foreclosure raises the demand for rental housing while keeping the supply of owner housing high, assuming that a household that gets foreclosed upon remains as a viable household, not folding itself into another household. ${ }^{21}$ Keeping the supply of owner housing high may be essential to discourage production and bring the housing market back to the long-run equilibrium.

\section{Prices and Oversupply}

The theory put forth in section 4 assumes that short-run deviations, or oversupply, is driven by deviations of prices from the long-run equilibrium. Oversupply is defined as the difference between the short-run and long-run vacancy rate. From equations (9) and (10) we can write oversupply as

$$
O S=\rho \varepsilon^{p} .
$$

In this section we focus on the owner-occupied market to examine how well prices can explain oversupply. Figure 13 plots biannual real house prices since 1975 from the Federal Housing Finance Agency (FHFA) House Price Index. ${ }^{22}$ Comparing figure 11 with figure 13, the oversupply in the owner-occupied market seems related to real house prices. In particular, in the owner-occupied market there are peaks in oversupply for all three peaks in the real house price index. The exception is that there is a period of oversupply from 1999-2003 that is not related to a peak in the house price index. ${ }^{23}$ At first glance there is evidence that prices can be driving oversupply in the owner-occupied market.

The price series clearly has trend growth. ${ }^{24}$ Therefore, to test whether price fluctuations are driving oversupply we need to detrend prices somehow. However, instead of using an exogenous estimate for trend growth in prices, we can use the estimated oversupply to both estimate trend growth in prices and how much price fluctuations drive oversupply.

\footnotetext{
${ }^{21}$ For instance, move in with family.

${ }^{22}$ The series was formally known as the 'OFHEO' house price index.

${ }^{23}$ Put differently, prices do not have a trough in 2005, whereas there is a trough in oversupply in 2005.

${ }^{24}$ Whether this is truly trend growth or quality adjustments does not matter for this analysis
} 


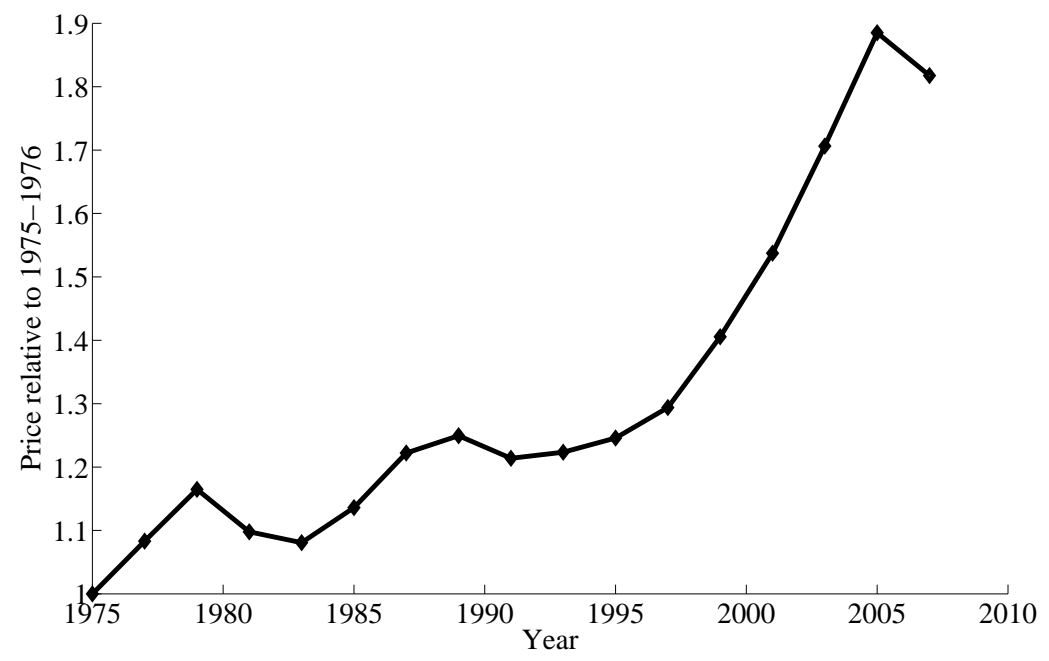

Figure 13: Real Housing Prices Biannual, source FHFA and BEA (GDP Deflator).

To see this, write the trend price ${ }^{25}$ as

$$
\bar{p}_{t}=(1+\mu)^{t} \bar{p}_{0}
$$

where $\bar{p}_{0}$ is the initial price level and $\mu$ is the annual growth in prices. The price shock, $\varepsilon_{t}^{p}$, is given by

$$
1+\varepsilon_{t}^{p}=\frac{p_{t}}{\bar{p}_{t}}
$$

Taking logs and inserting equation (19) we get

$$
\varepsilon_{t}^{p}=\log p_{t}-t \mu-\log \bar{p}_{0} .
$$

Combing equations (21) with equation (18) we arrive at

$$
O S_{t}=c_{0}+c_{1} t+c_{2} \log p_{t}
$$

where

$$
\begin{gathered}
c_{0}=-\rho \log \bar{p}_{0} \\
c_{1}=-\rho \mu
\end{gathered}
$$

and

$$
c_{2}=\rho .
$$

\footnotetext{
${ }^{25}$ This assumes a log-linear trend for prices. This is most likely false, but it serves as a starting point. For instance, the theory in this paper assumes that the long-run price depends upon the growth rate of households, and this has not been decreasing exponentially (although it has been close, see figure 2).
} 


\begin{tabular}{|l|c|}
\hline$\rho$ & 0.0165 \\
\hline$\mu$ & 0.0116 \\
\hline $\log \bar{p}_{0}$ & 0.0908 \\
\hline $\mathrm{N}$ & 14 \\
\hline$R^{2}$ & 0.808 \\
\hline $\bar{R}^{2}$ & 0.773 \\
\hline
\end{tabular}

Table 3: Results of OLS regression of Oversupply on Price Deviations, the three observations from 1995-2000 are removed.

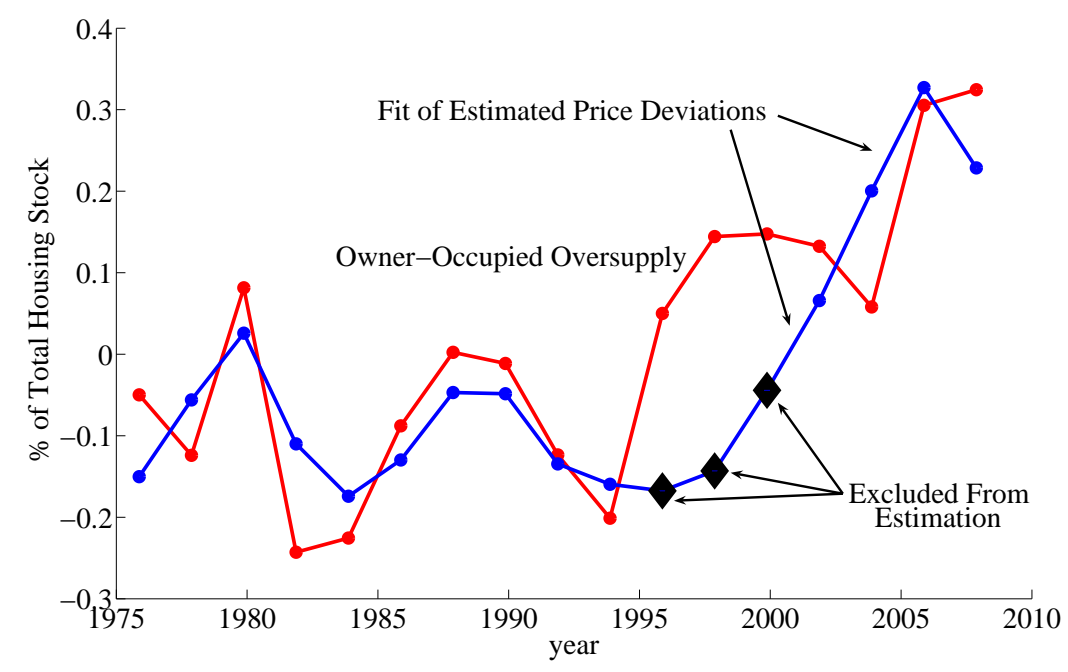

Figure 14: Fit of House Price Deviations to Oversupply

We can use OLS on equation 22 to get estimates for $\left\{\rho, \mu, \log \bar{p}_{0}\right\}$.

There is an issue in the estimation of equation 22: using the full sample we get an estimate for $\mu$ of $0.37 \%$. This seems too low and it implies that there is a trend in the estimated detrended price series. In the appendix I show that this is due to the oversupply from 1995-2000 driving the estimation to put a trend in the detrended estimate. The data also suggests that the oversupply from 1995-2000 may not be the true oversupply that builders are feeling. Since the mid 1960s the growth in homeowners in the Housing Vacancies survey tracks the construction of single family homes from the monthly survey of construction by Census. However, during the period 1995-2001 the increase in homeowners is significantly greater than the increase in single family home construction. This suggests that the estimated oversupply from 1995-2000 is picking up conversion from rental to owner occupied rather than construction. Therefore, for the estimates in this section the three observations from 1995-2000 are removed. 
Table 3 reports the results for the estimation using OLS. Figure 14 plots the fitted estimates from equation (22) alongside the estimated oversupply. Besides the period from 1995-2000, price deviations do a good job of explaining the movements in oversupply. For the restricted sample, the $R^{2}$ is 0.808 while the adjusted $R^{2}$ is 0.773 . Using the estimated coefficients from the restricted regression, the price deviations explain $46 \%$ of the movements in oversupply for the entire sample, including the period from 1995-2000. This evidence suggests that in the short run, there are deviations in prices from the costs of production that result in periods of oversupply (or undersupply). The estimate for $\rho$ is 0.0165 . This implies that a $10 \%$ deviation in prices from trend results in an oversupply of houses of $0.165 \%$. However, remember that figure 11 suggests that most of the oversupply shows up in the rental market, so that the true impact of price deviations on oversupply could be much greater due to new construction driving housing units to the rental market, creating vacancies in the rental market.

A common question in the recent boom and bust in the housing market is how much are houses overvalued? A common metric in use is prices relative to income or rents. As an alternative, here the estimated oversupply determines how much houses are overvalued. Using the estimated values for $\log \bar{p}_{0}$ and $\mu$ in table 3 we can construct the quarterly series for the real price level of houses relative to trend (this uses the FHFA data). The results are plotted in figure 15. Using this metric, at the peak, houses were $20.44 \%$ above trend and as of the end of the fourth quarter of 2008 they were still 3.6\% above trend. However, the more intersting question is how much prices will fall relative to their peak. The dashed line in figure 15 represents the average of the three minimima (1975, mid 1980s and mid 1990s) of price deviations from trend (roughly -11\%). Making the strong assumption that prices will fall down to the average minimum, then prices will fall a total of $32.0 \%$ relative to trend from peak to trough. As of the fourth quarter of 2008 prices has already fallen $16.8 \%$ so they still have $15.1 \%$ to fall relative to trend under this metric.

We should be careful when we say that prics will fall an additional $15.1 \%$ relative to trend. Since trend prices are rising then real prices would not fall the full $15.1 \%$. For instance, from table 3 , the annual growth in real prices is $1.16 \%$, so that if prices fall for two more years, then real prices need only fall an additional $12.8 \%$ to hit trend ${ }^{26}$

\section{Conclusion}

On the center stage of the economic collapse of the past couple of years is the housing market. For a recovery to begin in earnest stability in the housing market seems essential. But what is a stable housing market? Borrowing a concept from the labor literature, this paper provides an answer in the concept of a Beveridge curve. In the housing market, the Beveridge curve is the negative relationship between the residential vacancy rate and the growth rate of households. Such a negative relationship is found to hold in the

\footnotetext{
${ }^{26}$ The $12.8 \%$ is $15.1 \%$ less twice $1.16 \%$.
} 


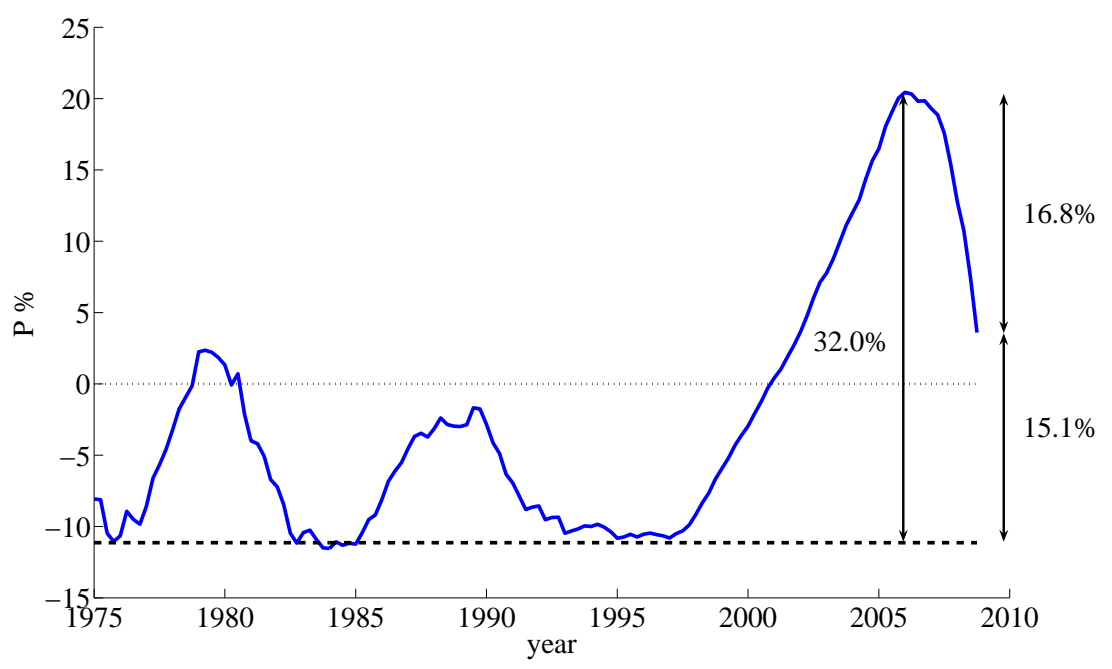

Figure 15: Estimated Price Deviations from Trend, Quarterly (FHFA)

owner-occupied market, the rental market, and the total housing market irrespective of ownership.

The existence of the Beveridge curve could simply be an artifact of history, with both the vacancy rate and the rate of household formation being driven by other factors that just happen to be correlated. However, we can also think of the relationship as representing a long-run supply condition. With such an interpretation, short-run deviations from the Beveridge curve denote a measure of disequilibrium in the housing market. As has been argued in the paper, this measure of disequilibrium is a good measure of oversupply in the housing market. For the total housing market irrespective of ownership, the estimates of oversupply point to three periods of oversupply since 1968: the 1973-1974 crisis; the mid to late 1980s; and the current crisis of 2007-2008. As a percentage of the total housing stock, the total oversupply in 2007-2008 was similar to 1973-1974. However, using a metric of years of oversupply the oversupply in 2007-2008 was unprecedented, suggesting substantial disequilibrium in the housing market, not a surprise.

Besides simply providing us with a measure of oversupply in the housing market, the analysis of the Beveridge curve provides us with some insight into the workings of the housing market. The first insight is that the rental market seems to be central to the adjustments of the housing market. Such a result is driven by the observations that (1) oversupply generally shows up in the rental market, not the owner-occupied market; (2) the oversupply in the rental market is twice as volatile as the oversupply in the owner-occupied market; and (3) in periods of oversupply for the total housing market, the oversupply first shows up in the rental market. In fact, in 2007-2008 over two-thirds of the total oversupply was in the rental market, not the owner-occupied market, and there was strong evidence 
of oversupply in the rental market in 2005-2006. The analysis suggests that the rental market seems to behave like a sponge, soaking up oversupply in response to overbuilding, and then letting it back out again when housing becomes scarce.

The second insight comes from focusing on the owner-occupied market. Using FHFA data on house prices, $45 \%$ of the movements in oversupply for the owner-occupied market can be explained by deviations of house prices from trend. Such a result lends support to the idea that in the short-run, supply considerations do not drive house prices, rather, that in the short-run house prices can deviate from fundamentals and drive housing supply. In particular, this result is consistent with the idea that bubbles can form in house prices, which leads to oversupply of houses. In the case of the recent behavior of the housing market, a bubble seems likely for the unprecedented oversupply of housing, particularly the the rise of the owner-occupied vacancy rate to $2.9 \%$.

As usual, a word of caution is advised. The empirical results come from noisy data, so noisy that biannual data had to be used. Also, the results are from national data. We would like to see the results at the regional or metropolition level. A quick examination of the regional Census data (it only starts in 1984) suggests that the Beveridge curve exists in the owner-occupied markets, but the results are weaker for the rental markets. However, there is some evidence that the combination of the Midwest and the West have a Beveridge curve in the rental market, suggesting a link between the two housing markets via the rental market.

Last, we need more work on modelling the supply side of the housing market taking into consideration the liquidity of the houses that the builders are constructing. The earlier empirical work of Topel and Rosen (1988) and DiPasquale and Wheaton (1994) both point to the importance of liquidity considerations. The results of this paper suggest that liqudity considerations can lead to substantial oversupplies of housing that we are now experiencing. These liquidity considerations are captured in a simple model in this paper developed to explain the existence of the Beveridge curve. However, the simple model put forth in this paper is insufficient for deeper analysis. It needs to be incorporated into

a more general model that includes households choosing to buy homes and endogenous price setting.

\section{References}

[1] Atkinson, C.(2009) "Econometric Applications of the Forward Search in Regression: Robustness, Diagnostics, and Graphics",Econometric Reviews,28:1,21 39

[2] Beveridge, W. (1944) Full Employment in a Free Society. London: George Allen and Unwin.

[3] Coulson, N. E. (1999) "Housing Inventory and Completion", Journal of Real Estate Finance and Economics 18(1) 89-105. 
[4] DiPasquale, D. and W. Wheaton (1994) "Housing Market Dynamics and the Future of Housing Price", Journal of Urban Economics, 35, 1-27.

[5] Fair, R. (1972) "Disequilibrium in Housing Models", Journal of Finance 27(2) 207221.

[6] Gabriel, S. and F. Nothaft (1988) "Rental Housing Markets and the Natural Vacancy Rate", AREUEA Journal 16(4) 419-429.

[7] Gabriel, S. and F. Nothaft (2001) "Rental Housing Markets, the Incidence and Duration of Vacancy and the Natural Vacancy Rate", Journal of Urban Economics 49(1) 121-149.

[8] Glaeser, E. and J. Gyourko (2007) "Housing Dynamics," HIER Discussion Paper \#2137.

[9] Glaeser, E., J. Gyourko and A. Saiz. (2008) "Housing Supply and Housing Bubbles," Journal of Urban Economics, 64 (2) 198-217.

[10] Hwang, M. and J. Quigley (2006) "Economic Fundamentals in Local Housing Markets: Evidence from U.S. Metropolitan Regions", Journal of Regional Science 46(3), 425453.

[11] Pissarides, C. (2000) Equilibrium Unemployment Theory Second Edition. MIT Press.

[12] Rosen, K. and L. Smith (1983) "The Price-Adustment Process for Rental Housing and the Natural Vacancy Rate", American Economic Review 73(4) 779-786.

[13] Shimer, R. (2005) "The Cyclical Behavior of Unemployment and Vacancies," American Economic Review 95(1) 25-49.

[14] Topel, R. and S. Rosen (1988) "Housing Investment in the United States" Journal of Political Economy 96(4) 718-740.

[15] Yashiv, E. (2008) "Beveridge curve" The New Palgrave Dictionary of Economics Second Edition. Eds. Steven N. Durlauf and Lawrence E. Blume. Palgrave Macmillan, 2008.

[16] Wheaton, W. (1990) "Vacancy, Search, and Prices in a Housing Market Matching Model," Journal of Political Economy 98(6) 1270-1292.

\section{A Construction of the Data}

Due to the rebenchmarking associated with the decenial census the raw data have jumps. To get around this, I construct a new series for the level of owners and then compute 


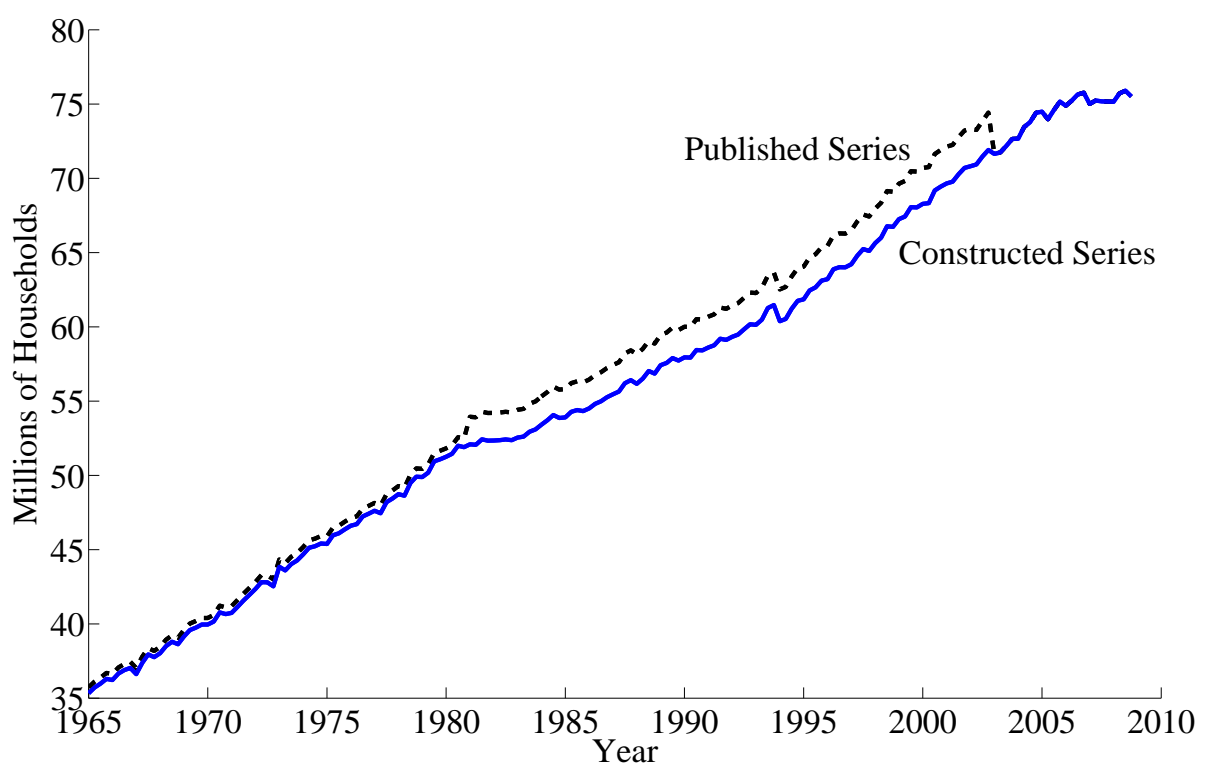

Figure 16: Published and Constructed Millions of Owners. Source: Census CPS/HV.

renters, vacant housing units for sale, and vacant housing units for rent, using, respectively, the homeownership rate, the owner-occupied vacancy rate and the rental vacancy rate.

When census rebenchmarks they create two sets of data for the year of the rebenchmarking. In this way a consistent series for the growth rates exists. Therefore, I create a consistent series for the level of owners throughout the sample by taking the last observation for owners, the 4th quarter of 2008, and, going backwards, construct a time series in levels using the growth rate of owners. There is one hitch in the owner time series: there is an unreasonably large annualized rise, $11.18 \%$, in owners in the first quarter of 1981. ${ }^{27}$ Thus, I assume that the annualized growth rate of owners from 1980:4 to 1981:1 is $1.5 \%$, the average of the two quarters before and the two quarters after. The resulting constructed series for the level of owners is plotted in figure 16 alongside the published series. The difference comes down to more households between the 1980 census and the 2000 .

I construct the level of total households and renters using the constructed series for owners and the published homeownership rate. I then use the published owner-occupied vacancy rate $^{28}$ and my constructed series of owners to construct a series for vacant units for sale. Likewise, I use the published rental vacancy rate and my constructed series for

\footnotetext{
${ }^{27}$ Census also does not provide a re-benchmarking for the 1980 census. The first quarter of 1981 seems early for this rebenchmarking but potentially this change is the 1980 census rebenchmarking.

${ }^{28}$ By published vacany rates I refer to the rate implied by the published values for the stocks of housing and the stocks of vacant housing, be they owner-occupied or rentals. Census also publishes a series for the the vacancy rates, but they only go to one decimal place.
} 
renters to construct a series for vacant units for rent. Last, I construct a series for the total vacancy rate, irrespective of ownership from

$$
\text { total vacancy rate }=\frac{\text { vacant for sale }+ \text { vacant for rent }}{\text { owners }+ \text { renters }+ \text { vacant for sale }+ \text { vacant for rent }} \text {. }
$$

I end up with a set of data that is consistent with the growth rates we observe in households as well as the composition of the households and housing units.

\section{B Estimation of Trend Prices}

In section 6 detrended prices were estimated using equation 22 with three observations removed. This section covers the rational behind, and the effects of, the removal of these observations. Equation 22, which is repeated here,

$$
O S_{t}=c_{0}+c_{1} t+c_{2} \log p_{t}
$$

where

$$
\begin{gathered}
c_{0}=-\rho \log \bar{p}_{0} \\
c_{1}=-\rho \mu
\end{gathered}
$$

and

$$
c_{2}=\rho .
$$

is estimated by using OLS to give estimates for the trend growth in prices. Recall that $\rho$ is sensitivity of oversupply to prices, $\mu$ is the annualized growth rate in trend prices, and $\bar{p}_{0}$ is the initial trend price level. However, the full sample estimation results in a trend to the supposedly detrended prices. To see this, figure 17 shows the fit of the estimate for equation 23 using the full sample (the dashed line). The implied price deviations are shown in figure 18 (the dashed line again). The estimated parameters are reported in table 4. Clearly, using the whole sample does not fully detrend prices.

The problem with the full estimation is that OLS is competing between two different estimations. One estimation is the one that is consistent with detrended prices. This is the estimate that is reported in the paper. The other estimation is trying to fit a trend to the detrended prices. This other estimation, which I refer to as the 'alternative', is inconsistent with theory, which can be considered grounds for rejecting this estimation.

To see the different estimations, figure 17 shows both the fit of equation (23) from the paper (dark line with large diamonds), and the the alternative (light line with large squares). The estimated price deviations from the paper (dark line) and the alternative (lighter line) are shown in figure 18. The estimate from the paper is arrived at by removing the three observations '95-'96,'97-'98, and '99-'00. The alternative estimate is arrived at by removing the observations '75-'76, '79-' 80 , and $03-^{-} 04$. All of the parameters from the estimations are reported in table 4 . The alternative is trying to fit a trend to the detrended prices. 


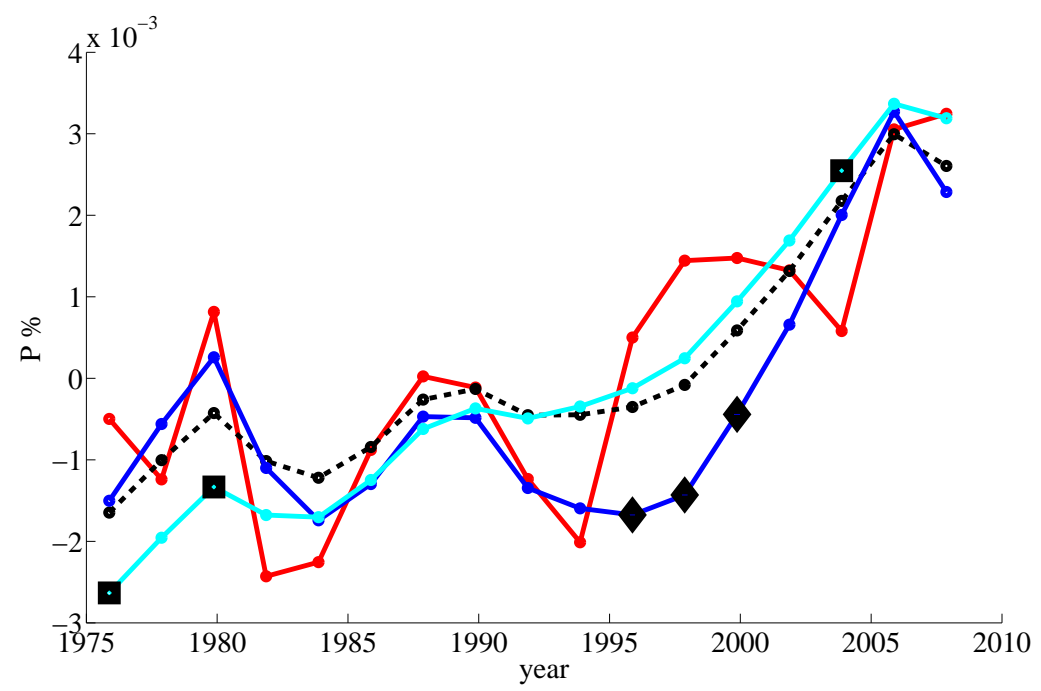

Figure 17: Different Fits of Estimation of Price Deviations and Oversupply Dashed line is the full estimation; dark line with large diamonds is estimation in paper,

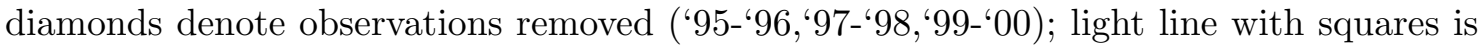
estimation with '75-'76, '79-'80, and '03-'04 removed (alternative); and red line (medium shade) is estimated oversupply from the paper.

Such a sensitivity of estimates to a few observations is a problem with working with so few observations, particularly with time series. This is the nature of the data used in this paper. This allows for a set of correlated observations such as '95-'96, '97-'98, and '99-'00 to have a large impact on the estimates. The three observations mask each other and allow for the standard OLS estimates to put some weight on the alternative estimate. The masking obsevations can be discovered by the use of 'Robust Estimations', that rely on using a subset of the observations. There are several quite nice systematic methods that can be used to find the masking observations. In particular I have used the methods in Atkinson (2009) to guide me. I have found that these methods aid the researcher in understanding where an estimation in small samples may be inconsistent with theory. The resulting robust regressions simply then reinforce the intuition from comparing the real house price series in figure 13 to the oversupply in the owner-occupied market in figure 11. The intuition is to connect the bottom of the troughs in figure 13 to get the price trend. This intuition is born out by the robust regression. Furthermore, the robust regression suggests that the estimated oversupply in '95-'96,'97-'98, and '99-'00 may be due to reasons other than construction. For instance, the large increase in owners at this time could instaed be due to conversion of rentals. This does seem true in the data where the growth rate of owners was abnormally more than construction. 


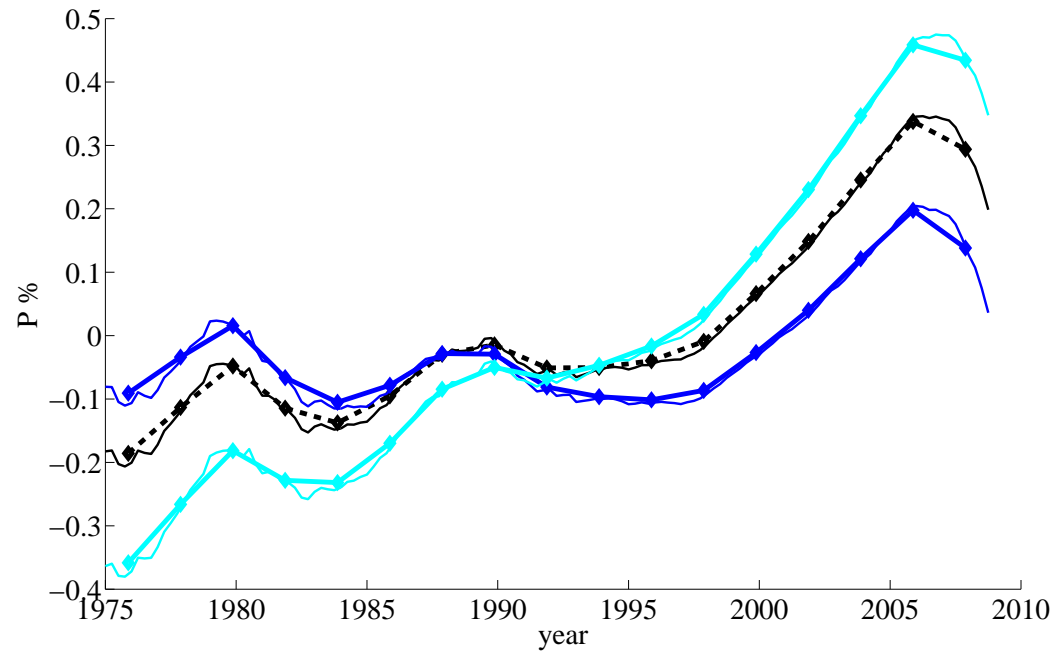

Figure 18: Estimated Price Deviations from Trend The dashed line is the full estimation, which shows a trend; the dark line is estimated deviations in trend from paper with '95-'96,'97-'98, and '99-'00 removed; lighter line is estimation with '75-'76, '79-'80, and '03-'04 removed which implies an unrealistic trend in the devations from trend (alternative). The smaller lines are the quarterly estimates.

\begin{tabular}{|l|c|c|c|}
\hline & Full Sample & Estimate of Paper & Alternative \\
\hline$\rho$ & 0.0089 & 0.0165 & 0.0073 \\
\hline$\mu$ & 0.0037 & 0.0116 & -0.0061 \\
\hline $\bar{p}_{0}$ & 1.2042 & 1.0950 & 1.4310 \\
\hline $\mathrm{N}$ & 17 & 14 & 14 \\
\hline$R^{2}$ & 0.6542 & 0.8077 & 0.8294 \\
\hline $\bar{R}^{2}$ & 0.6048 & 0.7728 & 0.7984 \\
\hline
\end{tabular}

Table 4: Results of OLS regression of Oversupply on Price Deviations, Different Subsamples 